\title{
FORMULASI SEDIAAN KRIM WAJAH BERBAHAN AKTIF EKSTRA METANOL BIJI KAKAO NON FERMENTASI (Theobroma cacao L) KOMBINASI MADU LEBAH
}

\author{
The Formulation of Face Cream Preparation from Extract of Non Fermented Cocoa \\ Beans Methanol (Theobroma Cacao L) Combined with Honey Bee
}

\author{
Medan Yumas \\ Balai Besar Industri Hasil Perkebunan \\ JI. Prof. Dr. Abdurahman Basalamah No. 28 Makassar \\ Pos-el: medan.yumas@yahoo.com
}

(Artikel diterima 6 Oktober 2016; direvisi 28 November 2016; disetujui 9 Desember 2016)

\begin{abstract}
Facial cream preparation contains active fotoprotector, antioxidant, and moisturizer derived from natural sources. Cocoa beans and honey bee are ones of anti-oxidant and moisturizer natural sources containing polyphenol/phenolic and other flavonoid compounds. Flavonoid contains anti-oxidant agent as free radical scavenger. The aim of this study was to obtain formula combination of non-fermented cocoa beans methanol extract and honey bee as active agents in effecting face skin moisturizing. Phases of the research consists of process of producing non-fermented cocoa beans methanol extract, producing face cream from non-fermented cocoa beans methanol extract and honey bee, and analysis on the characteristics of the products. The result showed that face cream formulated from $1.56 \%$ of non-fermented cocoa beans methanol extract and $2.34 \%$ of honey bee having $73.8 \%$ moisturizing effect in 60 minutes exposure does not irritate face skin and eyes. It has viscosity value $2.72 \times 10^{5} \mathrm{cps}$, has $\mathrm{pH}$ value 5.26 which is suitable with the range of normal $\mathrm{pH}$ for skin (4.5-7.5), does not contain residues of nipasol and nipagin, has scoring average $1-2.9$ by panelists on the attributes (aroma, consistency, texture, stickiness, homogeneous sensation, color, appearance, itchiness, erythema, easiness on cleaning, response on washing), and has total bacteria, khamir, and molod $5.0 \times 10^{2}$ which does not meet the requirements for skin moisturizer (SNI 16-4339-1996) i.e. 102 colonies/gram.
\end{abstract}

Keywords: non-fermented cocoa beans, honey bees, the active component, facial cream

ABSTRAK :Sediaan krim muka mengandung bahan aktif fotoprotektor, antioksidan, dan pelembab yang bersumber dari bahan alami. Biji kakao dan madu lebah merupakan salah satu sumber antioksidan alami dan bahan pelembab, mengandung senyawa-senyawa polifenol/fenolik dan flavonoid-flavonoid lainnya. Senyawa dari golongan flavonoid memiliki sifat antioksidan sebagai penangkap radikal bebas. Tujuan penelitian ini adalah mendapatkan kombinasi formula ekstrak metanol biji kakao non fermentasi dan madu lebah sebagai bahan aktif yang memberi efek melembabkan kulit muka. Tahapan penelitian terdiri dari proses pembuatan ekstrak metanol biji kakao non fermentasi, proses pembuatan krim muka berbahan aktif ekstrak metanol biji kakao non fermentasi dan madu lebah, serta analisis terhadap sifat-sifat produk yang dihasilkan. Hasil penelitian menunjukkan bahwaformula krim muka dengan bahan aktif ekstrak metanol biji kakao non fermentasi 1,56\% dan madu lebah 2,34\% memberikan efek melembabkan kulit muka dengan daya lembab 73,8\% dengan waktu pemaparan 60 menit, tidak memberikan iritasi pada kulit muka, dan tidak memberikan iritasi pada mata. Memiliki nilai viskositas $2,72 \times 10^{5} \mathrm{cps}, \mathrm{pH} 5,26$ sesuaikisaran $\mathrm{pH}$ normal kulit $(4,5-7,5)$,tidak mengandung residu nipagin dan nipasol, rata-rata penilaian panelis terhadap atribut(aroma, konsistensi, tekstur, lengket, sensasi homogen, warna, penampilan, rasa gatal, eritema, mudah dicuci, respon setelah mencuci) diterima baik oleh panelis dengan skor 1-2,9dantotal bakteridan kamir-kapang 5,0 x 10²belummemenuhi syarat mutu pelembab kulit (SNI 16-4399-1996) yaitu maksimum $102 \mathrm{koloni} / \mathrm{gram}$.

Kata kunci: biji kakao non fermentasi, madu lebah, komponen aktif, krim muka. 


\section{PENDAHULUAN}

Penuaan dini merupakan fenomena yang terjadi pada tubuh manusia dan menjadi bahan konsumsi public untuk diperbincangkan.Penuaan dini biasanya ditandai dengan kondisi kulit yang kering, bersisik, kasar dan disertai munculnya keriput dan noda hitam atau flek.Penuaan dini pada kulit terjadi secara alami, hal ini disebabkan oleh sumber radikal bebas yang berasal dari lingkungan seperti polusi udara, sinar matahari, gesekan mekanik, suhu panas atau dingin dan reaksi oksidasi yang berlebihan.Penyinaran matahari yang berlebihan menyebabkan jaringan epidermis kulit tidak cukup mampu melawan efek negatif seperti kelainan kulit mulai dari dermatitis ringans sampai kanker kulit, sehingga diperlukan perlindungan baik secara fisik dengan menutupi tubuh misalnya menggunakan payung, topi, atau jaket dan secara kimia dengan menggunakan kosmetika (Mokodompit, N.A, et.al., 2013).

Tubuh manusia memiliki system antioksidanuntukmengenal reaktivitas radikal bebas, yang secara berkelanjutan dibentuk sendiri oleh tubuh. Tetapi dalam keadaan tertentu tubuh tidak dapat mengatasinya sendiri sehingga tubuh memerlukan zat-zat antioksidan dari luar tubuh untuk mencegah terjadinya reaksi reaktif radikal bebas tersebut. Antioksidan merupakan senyawa yang mampu menangkal atau meredam dampak negatif oksidan dalam tubuh, yang bekerja dengan cara mendonorkan satu elektronnya kepada senyawa yang bersifat oksidan sehingga aktivitas senyawa oksidan tersebut dapat dihambat (Titta et al., 2013).

Salah satu upaya mengurangi dampak negatif penggunaan bahan aktif dari bahan kimia dalam krim wajah adalah menggunakan bahan aktif alami atau herbal. Kembalinya perhatian ke bahan aktif alami yang dikenal dengan istilah back to nature dianggap sebagai hal yang bermanfaat. Penelitian Sabir (2005) menunjukkan bahwa penggunaan bahan alami dapat mengurangi efek samping zat kimia pada tubuh, sehingga penambahan bahan alami tersebut dalam krim wajah dapat mendukung program pelayanan kesehatan wajah.

Biji kakao non fermentasi dan madu lebah merupakan bahan alam yang potensial untuk dijadikan bahan aktif pada produk kosmetik sebagai antioksidan, mencegah penuaan dini, anti jerawat, dan mencerahkan wajah.Biji kakao non fermentasi dan madu lebah mengandung senyawa polifenol terutama golongan flavonoid dan tannin yang bersifat antioksidan. Suryanto (2012) dan Sartini (2007) keduanya mengatakan bahwa senyawa flavonoid, katekin, epikatekin, dan tannin memiliki aktivitas antioksidan yang berpotensi sebagai tabir surya, penyegar kulit, dan pengatur keseimbangan radikal bebas yang bisa memperlambat proses penuaan. Menurut (Raga, 2012). Senyawa flavonoid memiliki sifat antioksidan sebagai penangkap radikal bebas karena mengandung gugus hidroksil yang bersifat sebagai reduktor dan dapat bertindak sebagai donor hidrogen terhadap radikal bebas.

Antioksidan dapat dimanfaatkan untuk memperbaiki sel-sel kulit yang rusak akibat radikal bebas dan menangkal radikal bebas.Antioksidan dalam bahan kosmetik dapat memberikan efek melembabkan dan mencerahkan kulit sehingga kulit tidak hanya terjaga kelembapannya namun terlihat bercahaya (Fauzi et al., 2012). Oleh karena itu, produk krim wajah yang bermanfaat bagi kesehatan muka menjadi prioritas tertinggi untuk dikembangkan dalam industri kosmetik. Salah satu produk kosmetik yang praktis dan mudah dikembangkan adalah krim muka berbahan aktif alami yang bersumber dari biji kakao non fermentasi kombinasi madu lebah.

Krim adalah produk kosmetik yang mudah dan praktis penggunaannya dan didefinisikan sebagai sediaan setengah padat yang mengandung satu atau lebih bahan obat terlarut atau terdispersi dalam bahan dasar yang sesuai. Umumnya produk krim terbentuk dari minyak yang dimasukkan ke dalam air pada fase minyak dan humektan yang lebih banyak dari produk lotion. Krim terdiri dari $15 \%$ - $40 \%$ fase minyak dan $5 \%-15 \%$ fase humektan, dengan 
karakteristik penampakannya hampir sama dengan produk lotion (Windarwati, 2011). Kemajuan ilmu pengetahuan dan teknologi menyebabkan berbagaiprodusen krim muka membuat inovasi untuk menambahkan zat lain yang bermanfaat bagi kesehatan wajah. Penambahan bahan aktif tertentu pada krim muka dapat mengurangi jumlah kerutan pada kulit muka dan bintik hitam atau flek serta melindungi kulit wajah dari paparan sinar matahari.

Beberapa penelitian yang berkaitan dengan pembuatan produk krim berbahan aktif alami telah dilakukan sebelumnya; misalnya : Aktivitas Antioksidan Krim Ekstrak Sari Tomat (Solanum lycopersikum L.,) oleh Alissya et al., (2013); Formulasi Krim Wajah Dari Sari Buah Jeruk Lemon (Citrus lemon L) Dengan Variasi Konsentrasi Emulgator, oleh Faradiba et.al., (2013); Formulasi Krim Antioksidan Ekstrak Etanol Bawang Hutan (Eleutherine palmifolia L. Merr) oleh Nela et al., (2013); Formulasi Krim Ekstrak Lida Buaya (Aloe vera) Sebagai Alternatif Penyembuhan Luka Bakar, oleh Risky A.W, et al., (2013); Formulasi Sedian Masker Gel Dari Ekstrak Etanol Daun Teh Hijau (Camellia sinensis L.) Dan Madu Hitam (Apidorsata) Sebagai Antioksidan, oleh Titta H.S., et al., (2013); dan Penentuan Nilai Sun Protective Faktor (SPF) Secara In Vitro Krim Tabir Surya Ekstrak Etanol Kulit Alpukat, oleh Ade et al., (2013). Namun pembuatan krim wajah berbasis bahan aktif dari ekstrak methanol biji kakao non fermentasi kombinasi madu lebah belum pernah dilakukan.

Terkait dengan berkembangnya produk krim wajah berbahan aktif dari bahan kimia dan meningkatnya konsumen akan pengaruh konsumsi kosmetik tersebut terhadap kesehatan kulit wajah maka perlu dipelajari dan dikembangkan produk krim muka berbahan aktif alami. Tujuan penelitian ini adalah untuk mempelajari dan mendapatkan kombinasi formula bahan aktif ekstrak methanol biji kakao non fermentasi dan madu lebah pada pembuatan krim wajah.

\section{METODOLOGI}

\section{Bahan}

Penelitian dilakukan di Balai Besar Industri Hasil Perkebunan Makassar. Bahanbahan yang digunakan dalam penelitian ini adalah biji kakao kering yang tidak difermentasi dari buah kakao yang diperoleh dari Kabupaten Luwu Provinsi Sulawesi Selatan; madu lebah diperoleh dari tempat penangkaran lebah di Kabupaten Kolaka Sulawesi Tenggara. Bahan ingredient untuk krim wajah meliputi ekstrak metanol biji kakao non fermentasi dan madu lebah sebagai bahan aktif alami, lemak kakao, minyak zaitun, asam stearat, cetyl alkohol, propilen glikol, gliserin, metil paraben, propil paraben, novemmer, aquadest bidestilat. Sedangkan bahan-bahan kimia yang digunakan untuk ekstraksi bahan aktif dari biji kakao non fermentasi, yaitu n-heksan (teknis) dan metanol p.a.

\section{Alat}

Alat-alat yang digunakan dalam penelitian ini adalah tempat penjemuran biji kakao non fermentasi,rotary evaporator, corneometer CM 825, waterbath, corong kaca (pyrex), kertas saring whatman no 41 , timbangan digital (sartorius), cawan petri, gelas ukur $1500 \mathrm{ml}$ (pyrex), erlen meyer $250 \mathrm{ml}$, gelas piala $250 \mathrm{ml}$ (pyrex) batang pengaduk kaca, winowing, panci stainles stell, mixer, termometer air raksa, kompor gas, pisau stainless steel, beaker gelas, kertas $\mathrm{pH}$, oven merek venticell 404 dan 222 MMM medcenter GmbH D 82152 Germany, vortex mixer merek Barnstead International, hot plate strirer cimarec II, incubator merek INB 500, vortex merek maxi mix II thermo, $\mathrm{pH}$ meter merek brench top $\mathrm{pH}$ meter GLP 21 crison, waterbath merek HH6 RRC, timbangan kapasitas $5 \mathrm{~kg}$.

\section{Metode Penelitian}

Penelitian ini terdiri atas 4 tahapan yaitu pembuatan biji kakao non fermentasi, ekstraksi komponen aktif dari biji kakao non fermentasi, pembuatan krim wajah, analisis krim wajah meliputi viskositas krim wajah, derajat keasaman, uji efek melembabkan, uji 
iritasi pada kulit, uji iritasi pada mata, dan uji organoleptik.

\section{Biji Kakao Non Fermentasi}

Buah kakao yang diperoleh dari Kabupaten Luwu Utara dibelah dengan menggunakan balok kayu untuk memisahkan biji kakao dari kulit buahnya. Biji kakao yang terpisah dari kulit buah dan pulp dikeringkan dibawah sinar matahari selama 5 hari dengan suhu $\pm 50^{\circ} \mathrm{C}$ sampai mencapai kadar air $7 \%$. Dilakukan proses pengecilan ukuran biji kakao dengan alat winowing diperoleh biji kakao dengan ukuran kecil-kecil. Biji kakao kering dengan ukuran yang kecil dijadikan bahan untuk diekstrak bahan aktifnya.

\section{Bahan Aktif (Komponen Aktif)}

Ekstraksi komponen aktif dari biji kakao non fermentasi dilakukan dengan cara maserasi. Ekstraksi diawali dengan pemisahan lemak kakao yang terdapat pada biji kakao non fermentasi menggunakan larutan n-heksan. Tujuannya adalah untuk menghilangkan lemak, wax, dan komponen lain yang tidak dibutuhkan yang terdapat di dalam biji kakao non fermentasi.Sebanyak 1 $\mathrm{kg}$ biji kakao non fermentasi dengan ukuran kecil-kecil direndam dengan n-heksan teknis sebanyak 1,5 liter $(1: 1,5)$ dan dibiarkan selama 24 jam pada suhu kamar. Biji kakao non fermentasi yang telah direndam, disaringmenggunakan kertas Whatman no 41 ke dalam wadah bersih sehingga diperoleh filtrat dan residu. Residu dalam bentuk biji kakao non fermentasi dengan ukuran kecil diangin-anginkan selama 5 hari pada suhu kamar untuk menghilangkan bau pelarut $n$-heksan. Kegiatan pemisahan lemak kakao dari biji kakao non fermentasi dengan ukuran kecil-kecil diulang sebanyak 3 kali. Sebanyak $1 \mathrm{~kg}$ biji kakao non fermentasi yang telah bebas dari bau pelarut $n$-heksan direndam kembali dengan 1,5 liter metanol p.a pada suhu kamar selama 48 jam sambil diaduk-aduk. Biji kakao non fermentasi yang telah direndam metanol, disaring kembali ke dalam wadah bersih menjadi filtrat 1 , residu kembali dimasukkan ke dalam wadah dan ditambahkan lagi metanol, diaduk dan disimpan selama 48 jam pada suhu kamar. Hasilnya kembali disaring menjadi filtrat
2. Kegiatan pemisahan komponen aktif ini diulang sebanyak 3 kali. Larutan metanol yang mengandung senyawa aktif dari biji kakao non fermentasi di rotary evaporator untuk membebaskan sisa bahan pelarut metanol sehingga diperoleh komponen aktif (senyawa aktif) yang masih bersifat gel atau kental.

\section{Pembuatan Krim Wajah}

Proses pembuatan krim wajah diawali dengan melakukan penimbangan bahan-bahan yang akan digunakan pada pembuatan krim wajah. Pada proses pembuatan krim wajah, formula dasar yang digunakan adalah modifikasi dari formula dan proses pembuatan produk krim Sartini (2013) dan Hasni Hasan (2008), dibagi ke dalam dua fase yaitu fase minyak dan fase air dengan tipe fase minyak yang dituang ke dalam fase air (m/a).Formulasi krim wajah disajikan pada Tabel 1.

Tabel 1. Formulasi krim wajah

\begin{tabular}{lcc}
\hline \multicolumn{1}{c}{ Bahan } & $\begin{array}{c}\text { Krim Wajah A } \\
\text { (\%) }\end{array}$ & $\begin{array}{c}\text { Krim Wajah B } \\
\text { (\%) }\end{array}$ \\
\hline Gliserin & 1,95 & 1,95 \\
Lemak Kakao & 2,925 & 2,925 \\
Minyak zaitun & 0,585 & 0,585 \\
Asam stearat & 1,95 & 1,95 \\
Cetil alkohol & 0,977 & 0,977 \\
Propil paraben & 0,02 & 0,02 \\
Aquadest & 82,41 & 82,41 \\
Propilen glikol & 4,875 & 4,875 \\
Metil paraben & 0,176 & 0,176 \\
Ekstrak & $\mathbf{2 , 3 4}$ & $\mathbf{1 , 5 6}$ \\
methanol biji & & \\
kakao non & & \\
fermentasi & & \\
Madu lebah & $\mathbf{1 , 5 6}$ & $\mathbf{2 , 3 4}$ \\
\hline
\end{tabular}

Fase minyak terdiri dari gliserin 1,95\%; lemak kakao 2,925\%; minyak zaitun $0,585 \%$; asam stearate 1,95\%; cetil alcohol 0,977\%; dan propil paraben $0,02 \%$. Fase air terdiri dari metil paraben $0,176 \%$; propilen glikol 4,875\%; aquadest $82,41 \%$.Fase minyak dan fase air merupakan variable tetap (konstan), sedangkan komponen aktif yang terdiri dari dari ekstrak methanol biji kakao non 
fermentasi dan madu lebah adalah variable tidak tetap (perubah). Konsentrasi ekstrak methanol biji kakao non fermentasi : madu lebah pada formula krim A adalah 2,34\%: $1,56 \%$ dan pada formula krim B adalah ekstrak methanol biji kakao non fermentasi: madu lebah adalah $1,56 \%: 2,34 \%$. Bahanbahan fase minyak dilebur di atas penangas air (waterbath) hingga suhu mencapai $70^{\circ} \mathrm{C}$. Saat mencapai suhu $70^{\circ} \mathrm{C}$ ditambahkan propil paraben dan tetap berada dalam waterbath dengan suhu konstan $70^{\circ} \mathrm{C}$.Pada waterbath yang lain dipanaskan bahan-bahan fase air hingga mencapai suhu $70^{\circ} \mathrm{C}$. Saat mencapai suhu $70^{\circ} \mathrm{C}$ ditambahkan propilen glikol dan metil paraben dengan tetap mempertahankan suhu $70^{\circ} \mathrm{C}$. Krim wajah dibuat dengan cara bahan-bahan fase minyak dituangkan sedikit demi sedikit ke dalam bahan-bahan fase air sambil diaduk dengan mixerdengan tetap mempertahankan suhu waterbath $70^{\circ} \mathrm{C}$. Setelah bahan-bahan fase minyak seluruhnya telah dituang ke dalam fase air dilanjutkan dengan menambahkan novemmer sebagai jembatan antara fase minyak dengan fase air. Pada saat novemmer telah ditambahkan, penangas air (waterbath) dimatikan, dan tetap terus di mixer. Pada saat mencapai suhu $45^{\circ} \mathrm{C}$ ditambahkan komponen aktif (ekstrak methanol biji kakao non fermentasi dan madu lebah) serta parfum dan tetap terus di mixer hingga dihasilkan produk krim wajah.

\section{Analisis Krim Wajah}

Analisis terhadap produk Krim wajah dengan bahan aktif ekstrak metanol biji kakao non fermentasi kombinasi madu lebah meliputi viskositas krim wajah, derajat keasaman, uji efek melembabkan, uji iritasi pada kulit, uji iritasi pada mata, dan uji organoleptic.

\section{a. Viskositas}

Pengukuran viskositas dilakukan dengan menggunakan 20 gram sediaan krim wajah. Alat yang digunakan adalah viskometer Brookfield dengan spindel TD dan TE, kecepatan $5 \mathrm{rpm}$ dengan waktu pengamatan 5 menit. b. Keasam-basaan $(\mathrm{pH})$

Pengukuran $\mathrm{pH}$ menggunakan $\mathrm{pH}$ meter.Rentang toleransi $\mathrm{pH}$ krim berkisar antara $4.0-7.5$.

c. Uji Mikrobiologi Angka Lempeng Total Dan Angka Kamir-Kapang

Sejumlah sampel uji : A dan B, masingmasing yang telah mengalami pengenceran tertentu, diinokulasikan pada media Nutrient Agar. Inkubasi pada suhu $37^{\circ} \mathrm{C}$ dan diamati selama 5 hari.Koloni yang tumbuh dihitung sebagai jumlah bakteri aerob yang terkandung pada sampel.

Sedangkan untuk analisis angka kamirkapang adalah sejumlah sampel uji: $A$ atau $B$, masing-masing yang telah mengalami pengenceran tertentu, diinokulasikan pada media Sabouraud Dextrosa Agar. Inkubasi pada suhu $20^{\circ} \mathrm{C}$ dan diamati selama 7 hari. Koloni yang tumbuh dihitung sebagai jumlah jamur yang terkandung pada sampel

\section{d. Uji Iritasi Pada Kulit}

Kelinci diperoleh dari peternakan kelinci di daerah Lembang.Kelinci yang digunakan adalah kelinci albino, galur New Zealand (hybrid), dengan bobot $>2$ kg.Kelinci diaklimatisasi terlebih dahulu selama 3 hari di Laboratorium Pemeliharaan Kelinci sebelum digunakan.Satu hari sebelum percobaan, punggung kelinci dibersihkan dari bulu dengan mencukur.Hanya kelinci dengan kulit sehat dan normal yang digunakan dalam percobaan.Selanjutnya disiapkan dua daerah uji pada punggung kelinci yang telah bersih dari bulu, masing-masing pada sisi kiri dan kanan.Pada masing-masing daerah uji dioleskan sejumlah masing-masing 500 mg sampel uji.Selanjutnya daerah uji ditutup dengan kasa hipoalergik, kertas selofan kemudian diperban dengan perban elastis. Kelinci dibiarkan dalam kadang dalam keadaan diperban selama 24 jam.Model uji yang digunakan adalah Uji tempel tertutup (Closed patch test).Tiap sampel diuji pada 3 kelinci.Sesuai panduan pengujian (WHO dan ISO 9003.10) pengamatan dilakukan pada $\mathrm{T}$ : 24, 48, dan 72 jam setelah pemberian sampel uji (A dan B). Parameter yang diamati adalah eritema-eskar dan udem serta efek -efek lain jika ada, kemudian diberi skor 
sesuai panduan pengujian. Berdasarkan skor eritema-eskar dan udem selanjutnya dihitung Indeks Iritasi Kutan Primer (IIKP). Sifat iritasi masing-masing sampel pada kulit ditentukan berdasarkan IIKP.

\section{e. Uji Iritasi Pada Mata}

Kelinci yang digunakan adalah kelinci yang memiliki mata sehat dan normal. Selanjutnya sejumlah 0,1 g masing-masing sampel uji krim wajah A dan krim wajah B ditempatkan pada kantong konjunctiva salah satu mata kelinci untuk masing-masing kelinci. Mata yang lain dari kelinci yang sama digunakan sebagai kontrol. Sesuai panduan pengujian (WHO dan ISO 1099310, 1995) pengamatan dilakukan pada $T$ 1, 24, 48, dan 72 jam setelah pemberian sampel. Parameter yang diamati adalah efek pada kornea (opasitas dan luas opasitas), efek pada iris, dan konjunctiva yang meliputi eritema, khemosis, dan lakrimasi serta efek efek lain jika ada kemudian diberi skor sesuai panduan pengujian. f. Uji Efek Melembabkan

Uji kelembapan dilakukan dengan menggunakan alat: Corneometer CM 825.

\section{g. Uji Organoleptik (Panelis)}

Uji panelis dilakukan pada 8 wanita dan 2 pria, dengan usia 19-40 tahun. Kriteria inklusi : wanita dewasa muda dengan tangan dan telapak tangan normal dan tidak memiliki riwayat alergi. Seluruh subyek terlebih dahulu mencuci tangan kemudian dikontakan dengan sampel krim wajah Adank krim wajah B. Sampel krim wajah A dank krim wajah B dibiarkan kontak selama 2 jam.

\section{HASIL DAN PEMBAHASAN}

\section{A. Viskositas Krim Wajah}

Nilai viskositas suatu bahan kosmetik menunjukkan kestabilan suatu produk yang dihasilkan.Nilai viskositas krim wajahdapat dilihat pada Tabel 2.

Tabel 2.Nilai viskositas produk krim wajah.

\begin{tabular}{|c|c|c|c|c|}
\hline $\begin{array}{c}\text { Krim } \\
\text { Wajah }\end{array}$ & Spindel & RPM & Nilai & Viskositas \\
\hline \multirow[t]{3}{*}{ A } & TD & 2,5 & 50,5 & $50.5 \times 800.000 \times 0.01=404.000 \mathrm{cps}$ \\
\hline & & & 51,0 & $51.0 \times 800.000 \times 0.01=408.000 \mathrm{cps}$ \\
\hline & & & 53,0 & $53.0 \times 800.000 \times 0.01=424.000 \mathrm{cps}$ \\
\hline Rataan & & & & $4.12 \times 10^{5} \mathrm{cps}$ \\
\hline \multirow[t]{3}{*}{ B } & TD & 2.5 & 32.5 & $32.5 \times 800.000 \times 0.01=260.000 \mathrm{cps}$ \\
\hline & & & 35.0 & $35.0 \times 800.000 \times 0.01=280.000 \mathrm{cps}$ \\
\hline & & & 34.5 & $34.5 \times 800.000 \times 0.01=276.000 \mathrm{cps}$ \\
\hline Rataan & & & & $2.72 \times 10^{5} \mathrm{cps}$ \\
\hline
\end{tabular}

Penentuan kekentalan dan penentuan viskositas pada sediaan krim adalah bahan-bahan yang digolongkan ke dalam fase minyak terutama lemak kakao, asam stearate, dan cetil alcohol.Bahan-bahan ini memiliki karakteristik padat pada suhu ruang (Rahmanto, 2011).Perubahan viskositas suatu produk sangat dipengaruhi perubahan fase dispers, medium dispers, emulgator, bahan tambahan lain, dan lingkungan. Kedua macam krim wajah yang dibuat pada penelitian ini mempunyai komposisi yang sama kecuali kosentrasi ekstrak methanol biji kakao non fermentasi dan madulebah yang. Hasil analisa viskositas krim wajah menunjukkan bahwa nilai krim A sebesar 4.12 x $10^{5} \mathrm{cps}$ dankrim B sebesar $2.72 \times 10^{5} \mathrm{cps}$ (Tabel 2). Krim B memiliki nilai viskositas lebih rendah dibandingkan dengan nilai viskositas krim A. Hal ini disebabkan karena pada krim $\mathrm{B}$ terdapat penambahan madu lebah dengan kosentrasi yang lebih tinggi dibandingkan pada krim A. Diduga salah satu sifat bahan yang dimiliki oleh madu lebah adalah memiliki kadar air yang tinggi, dimana bahan penyusun madu lebah adalah nectar. Dengan 
kondisi yang demikian,terjadi kenaikan kadar air di dalam madu lebah. Pada saat madu lebah digunakan sebagai bahan aditif pada krim wajah $B$ dengan konsentrasi yang tinggi menyebabkan terjadi kenaikan kadar air pada produk krim B. Dengan demikian, diduga volume air di dalam sampel krim B bertambah maka terjadi penurunan tegangan permukaan pada krim B akibatnya tidak ada lagi keseimbangan antara fase minyak dengan fase air yang terjadi di dalam krim B. Menurut Schmitt (1996), emulsifier memiliki gugus polar maupun non polar dalam satu molekul sehingga dapat mengikat minyak yang non polar dan disisi lain dapat mengikat air yang polar. Dengan kata lain terjadi keseimbangan antara komponen yang larut di dalam air dan yang larut di dalam minyak.

\section{B. Derajat Keasaman (pH)}

Hasil pemeriksaan pH kedua krim wajah dapat dilihat pada Tabel 3.

Tabel 3.pH rata-rata krim wajah

\begin{tabular}{cccc}
\hline $\begin{array}{c}\text { Krim } \\
\text { Wajah }\end{array}$ & Parameter & Hasil & Alat \\
\hline A & $\mathrm{pH}$ & 5,14 & \\
$\mathrm{~B}$ & & 5,26 & $\begin{array}{c}\mathrm{pH} \\
\text { meter }\end{array}$ \\
\hline
\end{tabular}

Nilai pH untuk ke duakrim wajah eksperimen (Tabel 3) yaitu5,14 dan 5,26. Nilai $\mathrm{pH}$ tersebut berada dalam kisaran nilai $\mathrm{pH}$ yang terdapat pada SNI 16-43991996 sebagai syarat mutu pelembab kulit $(4,5-8,0)$ dan kisaran $\mathrm{pH}$ normal kulit yaitu 4,5-6,5 (Rizky et al., 2013). Dengan demikian krim wajah yang dihasilkan relatif aman digunakan.Nilai $\mathrm{pH}$ penting untuk mengetahui tingkat keasaman dari sediaan krim wajah agar tidak mengiritasi kulit. Hal ini sejalan dengan hasil penelitian yang dilakukan Swastika, dkk (2013) dan Medan (2015) bahwa pH 5-6 yang dimiliki oleh krim tidak terlalu jauh dengan $\mathrm{pH}$ fisiologi kulit sehingga dapat diterima untuk digunakan pada kulit. Sediaan kosmetik harus memiliki $\mathrm{pH}$ yang sesuai dengan $\mathrm{pH}$ kulit yaitu antara 4,5-7,5 (Faradiba, 2013). Jika krim memiliki
$\mathrm{pH}$ yang terlalu basah dapat menyebabkan kulit bersisik, sedangkan $\mathrm{pH}$ yang terlalu asam dapat menyebabkan iritasi kulit. Dengan melihat nilai $\mathrm{pH}$ pada kedua krim wajah eksperimen, pada dasarnya tidak menunjukkan adanya perbedaan yang nyata diantara kedua nilai $\mathrm{pH}$ tersebut.Pemberian perlakuan konsentrasi bahan akti ekstrak methanol biji kakao non fermentasi dan madu lebahpada kedua krim wajah tidak berpengaruh nyata pada nilai $\mathrm{pH}$ kedua krim wajah tersebut.

\section{Uji Mikrobiologi Krim Wajah}

Hasil uji mikrobiologi kedua krim wajah dapat dilihat pada Tabel 4 .

Tabel 4.Hasil uji mikrobiologi krim wajah

\begin{tabular}{llcc}
\hline No & \multicolumn{1}{c}{ Jenis } & \multicolumn{2}{c}{ Jenis Krim Wajah } \\
\hline & Pemeriksaan & A & B \\
1. & $\begin{array}{l}\text { Angka } \\
\text { lempeng total }\end{array}$ & $8,2 \times 10^{2}$ & $5,0 \times 10^{2}$ \\
2. & $\begin{array}{l}\text { Angka kamir- } \\
\text { kapang }\end{array}$ & $1,0 \times 10^{2}$ & $5,0 \times 10^{2}$ \\
\hline
\end{tabular}

Uji total bakteri dan kamir-kapang pada kedua krim wajah pada Tabel 4 berada pada kisaran $1,0 \times 10^{2}$ sampai dengan $8,2 \times 10^{2}$, ini menunjukkan bahwa kedua krim masih ditumbuhi bakteri maupun jamur. Hal ini menjelaskan bahwa konsentrasi bahan aktif ekstrak methanol biji kakao non fermentasi dan madu lebah hanya menghambat pertumbuhan jenis bakteri dan jamur tertentu, tidak menghambat total pertumbuhan mikroba yang yang ada pada kedua krim wajah tersebut. Jumlah cemaran bakteri tidak sesuai dengan syarat mutu pelembab kulit (SNI 16-4399-1996) yaitu maksimum 102 koloni/gram.

Jenis bakteri yang pertumbuhannya tinggididugabakterigramnegatif.Bakterigram negatif pertumbuhannyatidak dipengaruhi oleh bahan aktif jenis fenol.Jenis bakteri ini memiliki tiga lapisan yaitu membrane luar, membrane dalam, dan lapisan pepridoglikan tipis dengan kandungan lipid yang tinggi 1121\% (Hawley, 2003 dalam Mulyatni, dkk., 2012) sehingga bahan aktif jenis fenol sulit untuk merusak ketiga membrane sel tersebut. 
Hal inilah yang menyebabkan senyawa bioaktif yang terdapat pada kedua krim yang bersumber dari ekstrak methanol biji kakao non fermentasi dan madu lebah tidak dapat menembus membrane sel sehingga tidak terjadi penghambatan pertumbuhan bakteri gram negatif.Medan dkk (2015), Justus, dkk (2014), dan Mulyatni, dkk (2012), bahwa ekstrak komponen bioaktif kulit dari buah kakao dan bubuk kakao non fermentasi paling efektif menghambat pertumbuhan bakteri gram positif dibandingkan bakteri gram negatif.

\section{Uji Efek Krim Wajah Terhadap Kulit}

Hasil uji kedua krim wajaheksperimen terhadapefek melembabkan kulit wajah disajikan pada Tabel 5.

Tabel 5. Hasil uji efek krim wajah

\begin{tabular}{ccc}
\hline $\begin{array}{c}\text { Waktu } \\
\text { Pemaparan }\end{array}$ & $\begin{array}{c}\text { Rata-Rata Daya Lembab } \\
\text { Krim Wajah } \\
\text { A }\end{array}$ & $\begin{array}{c}\text { Krim } \\
\text { Wajah B }\end{array}$ \\
\hline 0 Jam & 50,0 & 49,1 \\
0.5 Jam & 75,1 & 43,9 \\
1 Jam & 56,3 & 73,8 \\
1.5 Jam & 53,9 & 68,9 \\
2 Jam & 52,5 & 64,9 \\
\hline
\end{tabular}

Kesan lembab merupakan salah satu parameter penting dalam memilih krim wajah. Hasil pengukuran tingkat kelembaban krim wajah terhadap kulit ditunjukkan pada Tabel 5.

Nilai kelembaban krim wajah A meningkat pada pemaparan 0,5 jam sebesar 75,1 dan setelah itu mengalami penurunan. Sedangkan pada krim wajah B terjadi peningkatan nilai kelembaban pada pemaparan selama 1 jam sebesar 73,8 dan selanjutnya pada waktu pemaparan berikutnya mengalami penurunan nilai kelembaban namun tidak signifikan. Jika membandingkan antara nilai melembabkan krim wajah A dengan krim wajah B berdasarkan lama waktu pemaparan, maka krim wajah B memiliki daya lembab yang lebih baik dan memiliki waktu daya lembab lama dibandingkan dengan krim wajah $\mathrm{A}$. Hal ini menunjukkan bahwa pemberian bahan aktif ekstrak methanol biji kakao non fermentasi dan madu lebah memberikan efek terhadap kulit wajah manusia. Lamanya waktu krim B memberi efek melembabkan kulit dibanding dengan krim wajahA karena penambahan madu lebah dengan konsentrasi tinggi pada krim wajah B. Salah satu fungsi dari madu lebah selain memperbaiki luka adalah melembabkan kulit karena mengandung beberapa vitamin dan mineral lainnya yang berfungsi sebagai antioksidan. Salah satu fungsi antioksidan adalah memberi efek melembutkan dan melembabkan kulit serta memperbaiki struktur kulit.

\section{E. Uji Iritasi Kulit Dan Mata}

Hasil uji kedua krim wajah terhadap kulit disajikan pada Tabel 6, iritasi terhadap mata disajikan pada Tabel 7 dan Tabel 8, serta Gambar 1, Gambar 2, Gambar 3 dan Gambar 4.

Tabel 6. Hasil uji krim wajah terhadap kulit kelinci

\begin{tabular}{|c|c|c|c|c|c|c|c|c|c|c|c|c|c|c|}
\hline \multirow{3}{*}{$\begin{array}{c}\text { Krim } \\
\text { Wajah }\end{array}$} & \multirow{3}{*}{$\begin{array}{c}\text { Periode } \\
\text { pengamatan } \\
\text { (jam) }\end{array}$} & \multicolumn{4}{|c|}{ Kelinci 1} & \multicolumn{4}{|c|}{ Kelinci 2} & \multicolumn{4}{|c|}{ Kelinci 3} & \multirow{3}{*}{ TIKP } \\
\hline & & \multicolumn{2}{|c|}{ Kiri } & \multicolumn{2}{|c|}{ Kanan } & \multicolumn{2}{|c|}{ kiri } & \multicolumn{2}{|c|}{ kanan } & \multicolumn{2}{|c|}{ kiri } & \multicolumn{2}{|c|}{ Kanan } & \\
\hline & & $\bar{E}$ & $\mathrm{U}$ & $E$ & $U$ & $E$ & $U$ & $E$ & $U$ & $E$ & $U$ & $E$ & $U$ & \\
\hline \multirow{4}{*}{ A } & 0 & 0 & 0 & 0 & 0 & 0 & 0 & 0 & 0 & 0 & 0 & 0 & 0 & \multirow{4}{*}{0} \\
\hline & 24 & 0 & 0 & 0 & 0 & 0 & 0 & 0 & 0 & 0 & 0 & 0 & 0 & \\
\hline & 48 & 0 & 0 & 0 & 0 & 0 & 0 & 0 & 0 & 0 & 0 & 0 & 0 & \\
\hline & 72 & 0 & 0 & 0 & 0 & 0 & 0 & 0 & 0 & 0 & 0 & 0 & 0 & \\
\hline \multirow{4}{*}{ B } & 0 & 0 & 0 & 0 & 0 & 0 & 0 & 0 & 0 & 0 & 0 & 0 & 0 & \multirow{4}{*}{0} \\
\hline & 24 & 0 & 0 & 0 & 0 & 0 & 0 & 0 & 0 & 0 & 0 & 0 & 0 & \\
\hline & 48 & 0 & 0 & 0 & 0 & 0 & 0 & 0 & 0 & 0 & 0 & 0 & 0 & \\
\hline & 72 & 0 & 0 & 0 & 0 & 0 & 0 & 0 & 0 & 0 & 0 & 0 & 0 & \\
\hline
\end{tabular}

$\mathrm{E}=$ eritema - eskar $; \mathrm{U}=$ udem 
Formulasi Sediaan Krim Wajah ... (Medan)

Tabel 7. Hasil uji krim wajah A terhadap mata kelinci

\begin{tabular}{|c|c|c|c|c|c|c|c|c|}
\hline \multirow[b]{2}{*}{ Sampel } & \multirow{2}{*}{$\begin{array}{c}\text { Periode } \\
\text { penga- } \\
\text { matan }\end{array}$} & \multirow{2}{*}{$\begin{array}{l}\text { No. } \\
\text { Kelinci }\end{array}$} & \multicolumn{2}{|c|}{ Kornea } & \multirow{2}{*}{ Iris } & \multicolumn{3}{|c|}{ Konjunctiva } \\
\hline & & & Opasitas & $\begin{array}{c}\text { Luas } \\
\text { opasitas }\end{array}$ & & Eritema & Khemosis & $\begin{array}{l}\text { Lakri- } \\
\text { masi }\end{array}$ \\
\hline \multirow{15}{*}{ A } & \multirow{6}{*}{24 jam } & 1 & 0 & 0 & 0 & 0 & 0 & 0 \\
\hline & & 2 & 0 & 0 & 0 & 0 & 0 & 0 \\
\hline & & 3 & 0 & 0 & 0 & 0 & 0 & 0 \\
\hline & & Rataan & 0 & 0 & 0 & 0 & 0 & 0 \\
\hline & & Skor & \multicolumn{2}{|r|}{0} & 0 & & 0 & \\
\hline & & 1 & 0 & 0 & 0 & 0 & 0 & 0 \\
\hline & \multirow{4}{*}{48 jam } & 2 & 0 & 0 & 0 & 0 & 0 & 0 \\
\hline & & 3 & 0 & 0 & 0 & 0 & 0 & 0 \\
\hline & & Rataan & 0 & 0 & 0 & 0 & 0 & 0 \\
\hline & & Skor & \multicolumn{2}{|c|}{0} & 0 & & 0 & \\
\hline & \multirow{5}{*}{72 jam } & 1 & 0 & 0 & 0 & 0 & 0 & 0 \\
\hline & & 2 & 0 & 0 & 0 & 0 & 0 & 0 \\
\hline & & 3 & 0 & 0 & 0 & 0 & 0 & 0 \\
\hline & & Rataan & 0 & 0 & 0 & 0 & 0 & 0 \\
\hline & & Skor & \multicolumn{2}{|c|}{0} & 0 & & 0 & \\
\hline
\end{tabular}

Skor maksimum $(\mathrm{WHO})$ : kornea $=80$; iris $=10$; konjunctiva $=20$

Tabel 8. Hasil uji krim wajah B terhadap mata kelinci

\begin{tabular}{|c|c|c|c|c|c|c|c|c|}
\hline \multirow[b]{2}{*}{ Sampel } & \multirow{2}{*}{$\begin{array}{c}\text { Periode } \\
\text { penga- } \\
\text { matan }\end{array}$} & \multirow{2}{*}{$\begin{array}{l}\text { No. } \\
\text { Kelinci }\end{array}$} & \multicolumn{2}{|c|}{ Kornea } & \multirow[b]{2}{*}{ Iris } & \multicolumn{3}{|c|}{ Konjunctiva } \\
\hline & & & Opasitas & $\begin{array}{c}\text { Luas } \\
\text { opasitas }\end{array}$ & & Eritema & Khemosis & $\begin{array}{l}\text { Lakri- } \\
\text { masi }\end{array}$ \\
\hline \multirow{15}{*}{ B } & \multirow{5}{*}{24 jam } & 1 & 0 & 0 & 0 & 0 & 0 & 0 \\
\hline & & 2 & 0 & 0 & 0 & 0 & 0 & 0 \\
\hline & & 3 & 0 & 0 & 0 & 0 & 0 & 0 \\
\hline & & Rataan & 0 & 0 & 0 & 0 & 0 & 0 \\
\hline & & Skor & \multicolumn{2}{|c|}{0} & 0 & & 0 & \\
\hline & \multirow{10}{*}{72 jam } & 1 & 0 & 0 & 0 & 0 & 0 & 0 \\
\hline & & 2 & 0 & 0 & 0 & 0 & 0 & 0 \\
\hline & & 3 & 0 & 0 & 0 & 0 & 0 & 0 \\
\hline & & Rataan & 0 & 0 & 0 & 0 & 0 & 0 \\
\hline & & Skor & & 0 & & 0 & \\
\hline & & 1 & \multicolumn{2}{|c|}{0} & 0 & 0 & 0 & 0 \\
\hline & & 2 & 0 & 0 & 0 & 0 & 0 & 0 \\
\hline & & 3 & 0 & 0 & 0 & 0 & 0 & 0 \\
\hline & & Rataan & 0 & 0 & 0 & 0 & 0 & 0 \\
\hline & & Skor & \multicolumn{2}{|c|}{0} & 0 & & 0 & \\
\hline
\end{tabular}

Skor maksimum $(\mathrm{WHO})$ : kornea $=80$; iris $=10$; konjunctiva $=20$ 


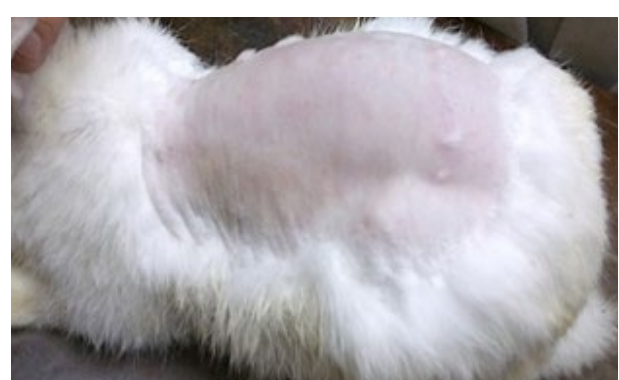

Gambar 1. Kulit kelinci sebelum pengolesan

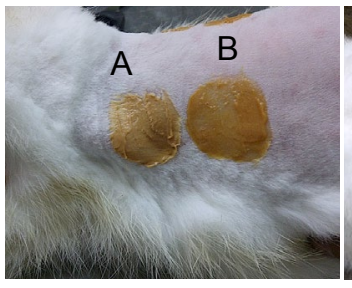

Gambar 2. Uji iritasi krim wajah pada kulit kelinci.

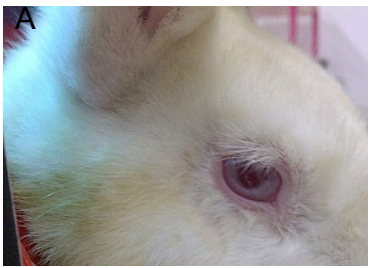

Gambar 4.Uji iritasi pada mata krim wajah A

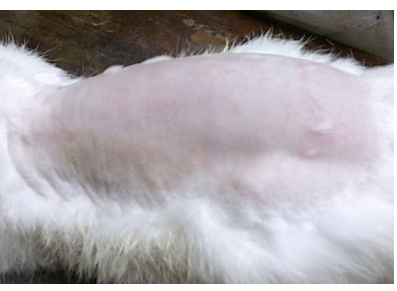

Gambar 3. Kulit kelinci setelah pengolesan

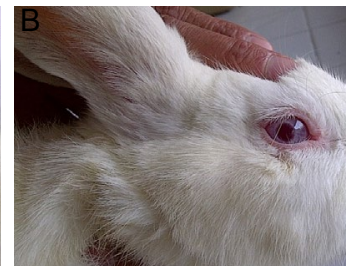

Gambar 5. Uji iritasi krim wajah B pada mata
Tabel 6, Gambar 1, dan Gambar 2, diatas menunjukkan bahwa baik krim wajah A maupun krim wajah B terhadap kulit, keduanya memberikan indeks Iritasi Kutan Primer $=0$. Sedangkan pada iritasi mata, dengan melihat parameter penilaian yaitu kornea, iris, dan konjunctiva (Tabel 7, Tabel 8, Gambar 3, Gambar 4, dan Gambar 5) kedua krim wajah tersebut memiliki nilai $=0$. Berdasarkan penilaian $\mathrm{WHO}$ yaitu kornea maksimum $=80$, iris maksimum $=10$, konjunctiva maksimum $=20$. Berdasarkan uji iritasi kulit dan mata menunjukkan bahwa kedua krim wajah tersebut dengan kategori tidak mengiritasi kulit dan mata.Hasil pemeriksaan iritasi terhadap kulit dan mata juga didukung hasil pemeriksaan derajat keasaman $(\mathrm{pH})$ Tabel 3, dimana kedua krim wajah tersebut tidak mengiritasi kulit karena nilai $\mathrm{pH}$ masih sesuai dengan nilai $\mathrm{pH}$ kulit yaitu antara 4,5-7,5. Halinimenunjukan bahwa baik bahan-bahan penyusun sediaan krim wajah, jenis bahan aktif maupun perbedaan konsentrasi bahan aktif, tidak memberikan efek atau pengaruh yang nyata terhadap timbulnya irtasi pada kulit dan mata. Menurut Fatmawati et al., (2012) bahwa beberapa bahan-bahan penyusun sediaan krim sperti gliserin adalah senyawa tidak toksit dan tidak menyebabkan iritasi sedangkan propilen glikol diperbolehkan digunakan sampai 15\% dari total berat bahan penyusun formula.

Dari Tabel 6, 7, 8, dan Tabel 9 menunjukkan bahwa efek iritasi pada kulit dan mata tidak dipengaruhi oleh tingkat perbandingan pemakaian (formulasi) antara ekstrak methanol biji kakao non fermentasi dan madu lebah sebagai bahan akti pada krim wajah. Dengan kata lain bahwa semakin tinggi atau rendah konsentrasi bahan aktif ekstrak methanol biji kakao non fermentasi dan madu lebahyang ditambahkan, tidak berpengaruh nyata terhadap efek iritasi kulit dan iritasi mata.Hal ini menunjukkan bahwa ekstrak methanol biji kakao non fermentasi maupun madu lebah keduanya bersumber dari bahan alami. Menurut BPOM (2007), bahwa penggunaan bahan aktif kimia sintetis dapat menimbulkan efek samping yang berbahaya seperti iritasi, kulit menjadi kemerahan (eritema), rasa terbakar, dan gangguan pigmentasi yang irreversibel.

\section{F. Uji Panelis Krim Wajah}

Hasil uji panelis yang dilakukan oleh 8 orang wanita dan 2 orang pria dengan usia 19 - 40 tahun terhadap respon pemakai ke dua produk krim wajah eksperimen terlihan pada Tabel 9. Kriteria uji meliputi aroma, konsistensi, tekstur, lengket, sensasi, warna, rasa gatal, eritema, mudah dicuci, dan respon setelah mencuci. 
Tabel 9. Hasil uji panelis terhadap krim wajahA dan krim wajah B

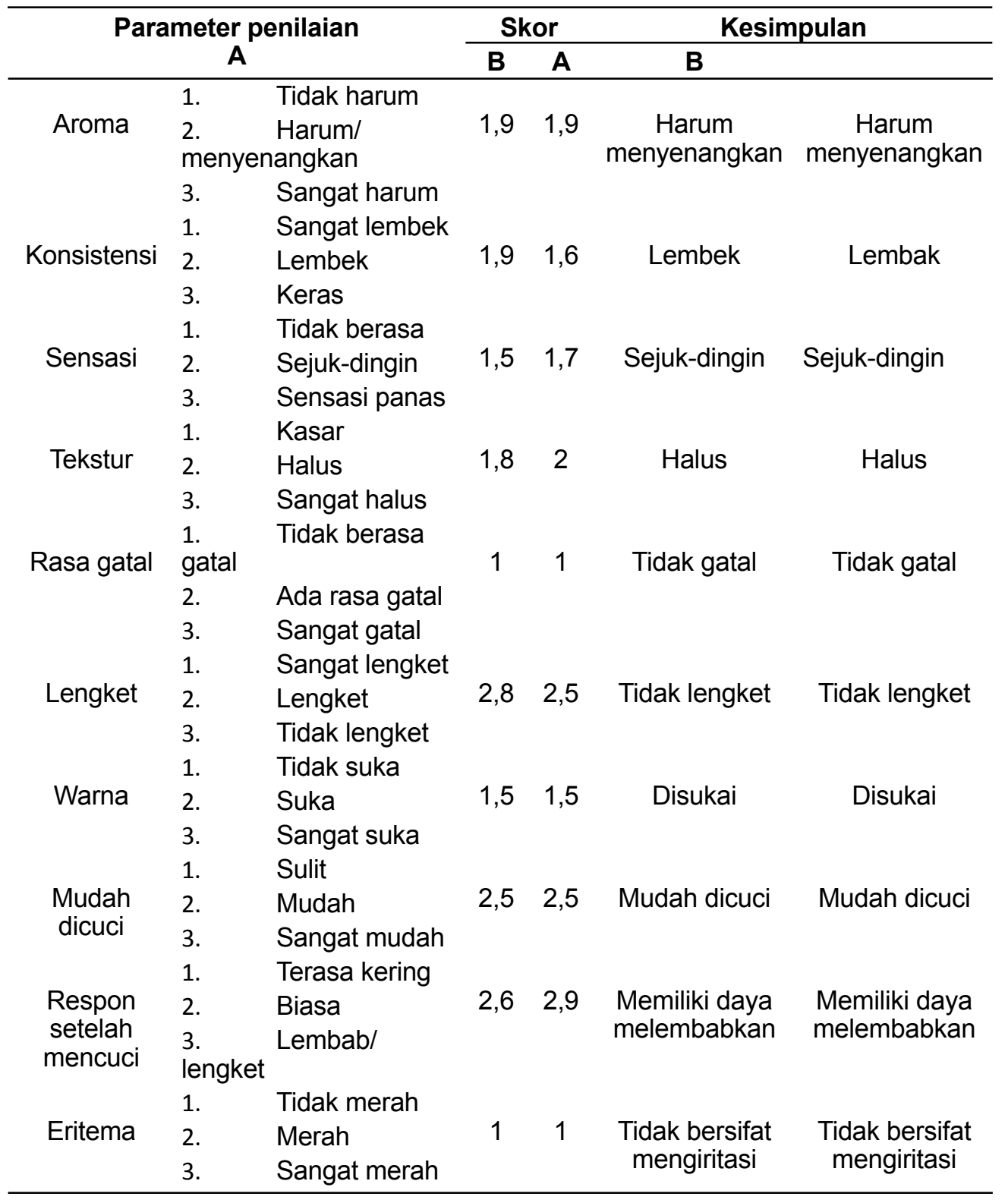

Pada Tabel 9 dapat dilihat bahwa keseluruhan parameter uji yang diberikan penilaian oleh panelis, semuanya masuk kategori penerimaan disukai oleh panelis (8 wanita dan 2 pria, dengan usia 19-40 tahun). Ini menunjukkan bahwa kedua krim muka tersebut, penggunaannya diterima oleh konsumen dari umur usia muda hingga umur usia menengah baik pria maupun wanita. Dari dua krim wajah yang ditawarkan kepada konsumen atau panelis, krim wajah B yang paling disukai oleh konsumen atau panelis. Hal ini menunjukkan bahwa ada hubungan yang bermakna antara kesukaan konsumen atau panelis dengan formulasi krim wajah $B$ berbahan aktif ekstrak methanol biji kakao non fermentasi dan madu lebah dengan kata lain bahwa konsumen atau panelis memiliki kesukaan yang sama dan konsistensi terhadap keseluruhan parameter uji yang diberikan.

Krim wajah A dan krim wajah B keduanya tidak terdapat perbedaan yang bermakna, namun krim wajah B yang paling disukai olehkonsumen atau panelis karena memiliki daya pelembab yang tinggi (Tabel 5) dan tidak menimbulkan efek iritasi pada kulit maupun pada mata (Tabel 6 , Tabel 7 , dan 
Tabel 8).Hal ini disebabkan karena seluruh konsentrasi bahan-bahan yang digunakan pada formulasi krim wajah B masih dibawah nilai ambang batas atau masih diperbolehkan.

\section{SIMPULAN}

Formula krim wajah ekstrak methanol biji kakao non fermentasi dan madu lebah terbaik dan disukai oleh panelis atau konsumen adalah formula krim wajah B yang terdiri dari gliserin 1,95\%; lemak kakao $2,925 \%$; minyak zaitun 0,585\%; asam stearate $1,95 \%$; cetil alcohol $0,977 \%$; propil paraben $0,02 \%$; aquadest $82,41 \%$; propilen glikol 4,875\%; metil paraben $0,176 \%$; ekstrak methanol biji kakao non fermentasi $1,56 \%$; dan madu lebah 2,34\%. Krim wajah $\mathrm{B}$ tersebut memiliki nilai viskositas $2,72 \times 10^{5}$ cps, memiliki pH 5,26 sesuai SNI16-43991996 danpH kulit 4,5-7,5 , angka lempeng total dan angka khamir-kapang $5 \times 10^{2}$.

Pemberian krim wajah $\mathrm{B}$ memberikan efek melembabkan dengan daya lembab 73,8 selama 1 jam, tidak menimbulkan iritasi kulit, tidak menimbulkan iritasi mata, tidak menimbulkan rasa gatal, dan tidak menimbulkan eritema serta panelis memberikan penilaian suka.

\section{DAFTAR PUSTAKA}

1. Ade, N.M., Hosea, J.E., dan Weny, W., 2013. Penentuan Nilai Sun Protective Factor (SPF) Secara In Vitro Krim Tabir Surya Ekstrak Etanol Kulit Alpukat. Pharmacon Jurnal IImiah FarmasiUnstrat Vol. 2 No. 3.

2. Alissya, S., Murfod, dan Purwanto. 2013. Aktivitas Antioksidan Krim Ekstrak Sari Tomat (Solanum lycopersicum L.). Traditional Medicine Journal, vol 18(3); hal : 132-140.

3. Badan Standardisasi Nasional. 1996. Sediaan Tabir Surya. SNI 16-4399-1996, Jakarta.

4. Badan POM RI. 2006. Kosmetik Yang Mengandung Bahan dan Zat Warna Berbahaya.

5. Fauzi, Aceng R, Nurmalina, dan Rina. (2012). Merawat Kulit dan Wajah. Jakarta: Gramedia.
6. Fatmawati, A., Ermina P., dan Michrun, N. 2012. Sains dan Teknologi Kosmetik. Makassar.

7. Faradiba, Faisal, A., dan Ruhama, M. 2013. Formulasi Krim Wajah Dari Sari Buah Jeruk Lemon (Vitis vinifera L.) Dengan Variasi Konsentrasi Elmugator. Majalah Farmasi dan Farmakologi, Vol. 17 No. 1; hal : 17-20.

8. Hasni Hasan, N., 2008. Pembuatan Alas Bedak Rose (Tidak Dipublikasikan). Laboratorium Terpadu Program Profesi Apoteker. Fakultas Farmasi Unhas, Makassar.

9. ISO 10993-10-1995. Biological Evaluation of Medical Devices-Part 10; test for irritation and sensitization, Genewa, 1995, 2-5.

10. Justus, E.L., dan Medan, Y. 2014. Ekstraksi Komponen Aktif Kulit Buah Kakao Dan Pemanfaatannya Sebagai Bahan Pengawet Alami Pada Produk Makanan. Jurnal Industri Hasil Perkebunan Vol. 9 No. 1 Juni 2014; 5967

11. Medan, Y., Sitti, R., dan Mamang. 2015. Formulasi Lulur Krim Dari Bubuk Kakao Non Fermentasi Dan Efek Terhadap Kulit. Jurnal Biopropal Industri, Vol 6 No. 2; 63-72.

12. Mokodompit, N.A, Edy, J.H, dan Wiyono, W. 2013. Penentuan Nilai Sun Protective Factor (SPF) Secara In Vitro Krim Tabir Surya Ekstrak Etanol Kulit Alpukat. Jurnal IImiah Farmasi-UNSTRAT Vol. 2. No.03. ISSN 2302-2493.

13. Mulyatni, S.A., Budiani, A., dan Taniwiryono, D. 2012. Aktivitas Antibakteri Ekstrak Kulit Buah Kakao (Theobroma cacao L.) Terhadap Escherichia coli, Basilus subtilis, dan Staphylococcus aureus. Jureus. Jurnal Menara Perkebunan. 80(2), 77-84.

14. Nela, S., Syariful. A., dan Yuliet,. 2013. Formulasi Krim antioksidan Bawang Hutan (Eleutherine palmifolia L. Merr). Online Jurnal of Natural Science, Vol 2 (3) : 111-112.

15. Rizky, A.W., Latifa., dan Winarni, P. 2013. Formulasi Krim Ekstrak Lidah Buaya (Aloe vera) Sebagai Alternatif Penyembuhan Luka Bakar. Indonesian Journal of Chemical Science. 
16. Raga, Y.P. 2012. Respons Pertumbuhan Dan Hasil Bawang Sabrang (Eleutherine americana Merr) Pada Beberapa Jarak Tanam Dan Berbagai Tingkat Pemotongan Umbi Bibit. Jurnal Online Agroteknologi.

17. Sabir, A. 2005. Aktivitas Antibakteri Flavonoid Propolis Trigona sp Terhadap Bakteri Streptococcus mutans Secara In Vitro. Majalah Kedokteran Gigi.

18. Sartini dan Gemini, A. 2007. Ekstraksi Komponen Bioaktif Dari Limbah Kulit Buah Kakao Dan Pengaruhnya terhadap Aktivitas Antioksidan Dan Antimikroba. Jurnal Fakultas Farmasi Unhas; hal 1-6.

19. Sartini. 2013. Pemanfaatan Kakao Sebagai Sumber Bahan Aktif Pembantu Sediaan Farmasi (Obat dan Kosmetika) dan Suplemen Makanan. Prosiding Seminar Nasional Teknologi Industri Kakao dan Hasil Perkebunan Lainnya. Balai Besar Industri Hasil Perkebunan Kementerian Perindustrian.

20. Schmitt, W.H. 1996. Skin Care Products. Di dalam Williams DF and Schmitt WH, editor. Chemistry and Tecnology of The Cosmetics and Toiletriesindustry. 2nd Ed. London : Blackie Academe and Profesional.

21. Suryanto, E. 2012. FitokimiaAntioksidan. Surabaya : Putra Media Nusantara.

22. Swastika, A., Mufrod dan Purwanto. 2013. Aktifitas Antioksidan Krim Ekstrak Sari Tomat. Ttradisional Medicine Journal 18(3), 132-140.

23. Titta H.S., Ahmad N., Resi A., (2013). Formulasi Sediaan Masker Gel Dari Ekstrak Metanol Daun Teh Hijau (Camellia sinensis L.) Dan Madu Hitam (Apidorsata) Sebagai Antioksidan. Kartika Jurnal IImiah Farmasi : 1(17-23).

24. Windarwati, S. 2011. Pemanfaatan Fraksi Aktif Ekstrak Tanaman Jarak Pagar Sebagai Zat Antimikroba dan antioksidan Dalam Sediaan Kosmetik. Tesis. Sekolah Pascasarjana Institut Pertanian Bogor. Bogor. 